Fifth International Conference on Sustainable Construction Materials and

Technologies. http://www.claisse.info/Proceedings.htm

\title{
The Performance Testing of Earthen Materials: Challenges and Future Developments
}

\author{
Antonin Fabbri ${ }^{1}$ and Jean-Claude Morel $^{2}$ \\ ${ }^{1}$ LTDS, UMR 5513 CNRS, ENTPE, 2 rue Maurice Audin, 69100 Vaulx-en-Velin, \\ France \\ ${ }^{2}$ Coventry University, Centre for the Natural and Built Environment, Priory Street, \\ CV1 5FB, Coventry, $U K$ \\ E-mail:antonin.fabbri@entpe.fr and jean-claude.morel@coventry.ac.uk
}

\begin{abstract}
Modern earth buildings are still a niche market despite their great potential to tackle some of the future challenges of the world housing shortage. The paper will discuss how to assess the engineering limitations of earthen architecture and the challenges faced by its development. As with any construction materials, it is crucial to know the limitations of the material to design and build safely. This is still an issue for earthen architecture, due to the variability of earths (local soils) and the lack of standard testing procedures. In this context, we will explain the work driven by the RILEM Technical committee 274-TCE.
\end{abstract}

Keywords: laboratory testing procedure, compressive strength, vapour permeability, moisture buffering, round Robin test.

\section{INTRODUCTION}

The modern earth architecture originates from an observation of the great number of existing heritage earth constructions in Europe. This wealth heritage is described, for example, by (Loti and Mecca, 2011), as evidence of using vernacular green building materials to deliver a successful and sustainable way of building. Being aware of the quality and quantity of this existing heritage, and using the ideas of past builders who had benefited for thousand years of empirical know-how, some modern architects propose to integrate this vernacular material in the current socio-technical system and ask for the latest scientific and technological development to produce cost-effective earth-based building products. Low energy in the production and circular economy thinking which were obvious in vernacular construction requires now innovation to be implemented in the current built environment.

There are different techniques used to build with earth; however, clay is always the main binder whatever the technique. We can distinguish the "dry" manufacture process where the earth is compacted, and "wet" manufacture process where the earth is 
moulded or extruded or stacked (Hamard et al. 2016). We can also distinguish techniques using small blocks (compressed earth blocks or adobes) implemented with a mortar to build masonry structures, and earth implemented in monolithic walls. In that case we can have rammed earth (Figures 1 and 2) which is a clayey soil (usually less than $20 \%$ of clay by dry weight of soil) compacted into formworks with a water content varying with soils, but within the range of $4-20 \%$ by dry weight of soil ("dry" process). We also have cob which usually needs soil with a higher content of clay and higher water content of the mixture than rammed earth ("wet" process). Cob sometimes may also contain some kind of fibrous organic material (typically straw) and sometimes lime.

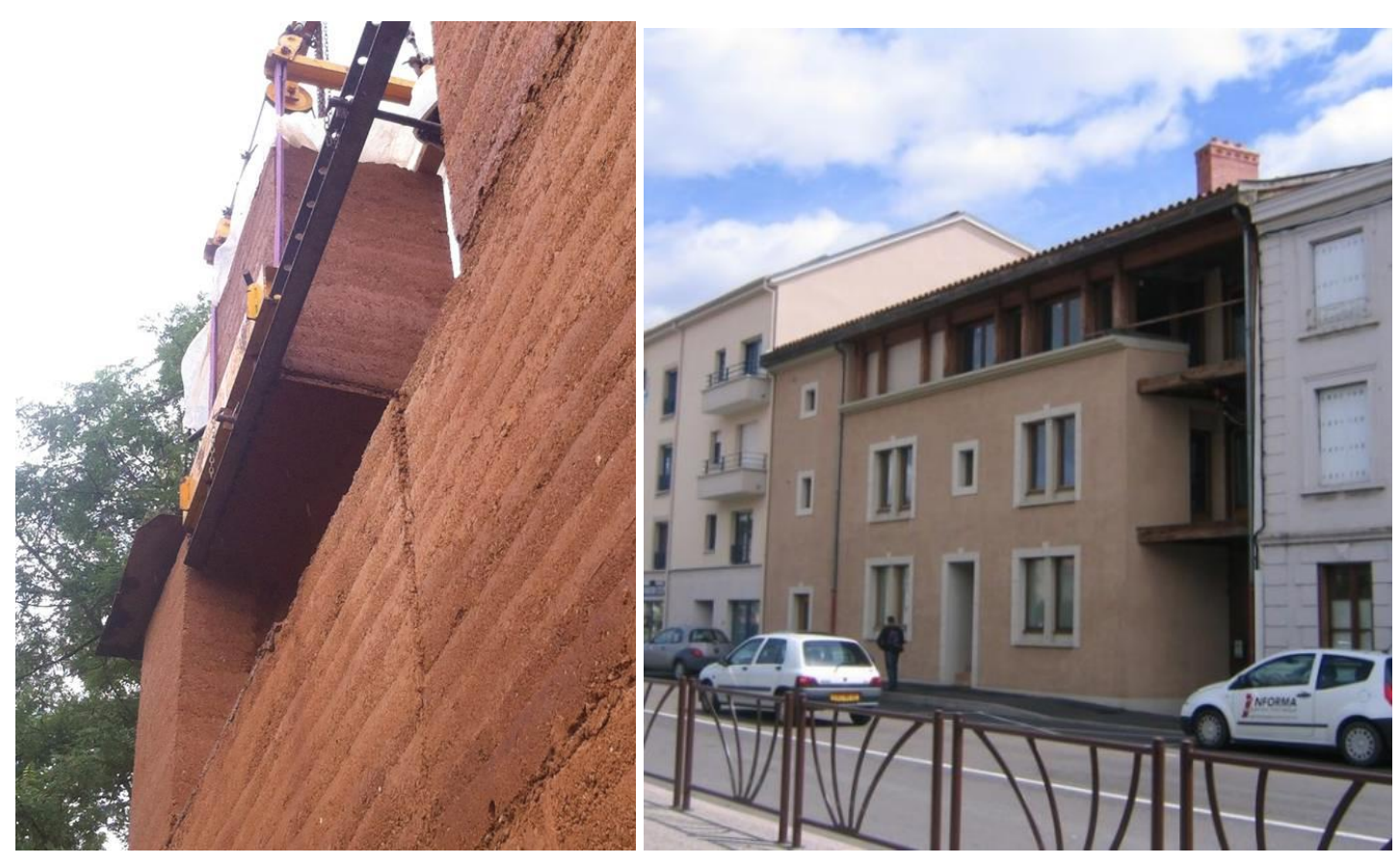

Figure 1. Implementation of prefabricated unstabilised rammed earth walls (left); A completed building of 9.4 metres height with external render and traditional appearance built in 2011 (right). (C) Nicolas Meunier.

The continuous clayey matrix plays the role of the binder between all these constituents and thus provides cohesion and strength. But the connections between the constituents are not perfect and some small voids, called pores, are embedded within the solid material. The network formed by the connection of these voids, called the 
porous network, enables fluids (either liquid or gas) to flow through the material. Due to this property, earthen material is a porous medium with a quite low resistance to the vapour and liquid transfers. In addition, clays and fibres are by themselves porous media. Their high affinity with water molecules allows capillary condensations or adsorptions phenomena. Thanks to the combination of these two processes (vapour transport and in-pore water sorption/desorption), earthen materials are hygroscopic. In other words, raw earth has a great potential to regulate indoor relative humidity levels. The latent heat associated with the sorption/desorption phenomena can also strongly modify the thermal behaviour of the material. Finally, these hygroscopic behaviour impacts the mechanical characteristics of the material. For example, the interactions of clay particles and/or fibres with the water molecules can be responsible for complexities in mechanical behaviours, such as swelling and shrinkage (Van Damme, 2002; Lei, et al., 2014). In addition, the mechanical resistance of soil decreases with its water content (i.e. the mass of water on the mass of dry solid) which is well known in soil mechanics, but it also applies to earth buildings. It seems, therefore, that the water content in raw earth materials is crucial to predict its behaviour.

The relevance of building with earth in the XXIth century is already shown in some showcase built in Switzerland (by Martin Rauch), France (by Nicolas Meunier) and China (by Lu Wenyu and Wang Shu) among others. The use of local earth as building materials enables to divide the embodied energy of a house by two and divide the transportation by 4.5 (Morel et al. 2001), without increasing the energy consumption during the service life of the building. Moreover, earth architecture delivers high positive impacts on socio-economy (Floissac et al. 2010). Although there are a growing number of new earth buildings, their prospects of entering mainstream construction as the main structural materials are limited due to different types of barriers. Although there is a sharp increase in scientific publications on the topic (Figure 2), one of those barriers is the lack of standard testing procedures. This lack has motivated the start of a Rilem technical committee (274-TCE) on "Testing and characterisation of earth-based building materials and elements". This paper will expatiate on this TC.

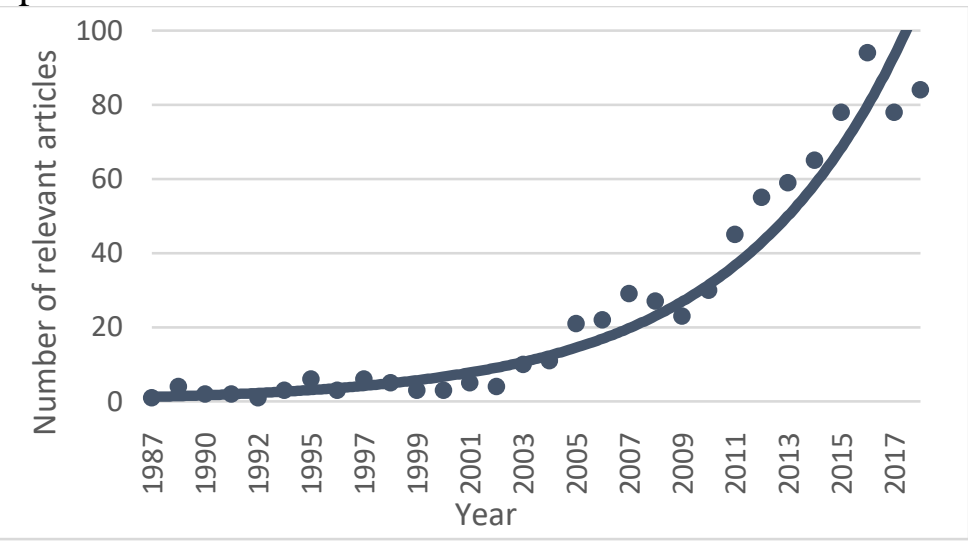

Figure 2. Journal papers related to earth architecture published every year, from Scopus. 


\section{THE RILEM TECHNICAL COMMITTEE 274-TCE}

\section{Definition of the TC subject and of the studied material}

The goal of this TC is to set up testing procedures for unstabilized earth as a building construction material. A good understanding of the earthen constructions requires taking into account their large variability and limitation. The first reason for this variability is that the local soils are used as building materials. The local soils are variable depending on the pedology of the site, and the construction of earth buildings cannot be totally included in an industrial process. Then partly to adapt the building technique to the different soils, several constructions technics have been invented, which is the second reason for the variability.

In those conditions, it is common sense to adapt the technics and architecture to the material available and not the contrary as it is in the modern industrial approach. That is why the principal concern is the evaluation of the performances (sustainability, strength, seismic resistance, thermal, moisture buffering) of the material as it is with very few modifications of its composition. For the moment, the performances are estimated through some common existing experimental methods: unconfined compressive strength to assess the mechanical, sorption/desorption curves and dry/wet cups for vapour adsorption and diffusion, hot wire or hot place for thermal conductivity, etc.... These studies underline an important variability of the measured parameters. Numerous reasons for these disparities can be intuited like the lack of hygrometry and temperature control during the tests, the differences in samples manufacture, geometry, and in test protocol... As an example, in the function of the experimental protocol used, an unconfined compressive test can lead to compressive strength up to 40MPa for earthen material (Aubert, et al. 2013), which is not realistic. In addition, the knowledge of these common parameters is found to be insufficient to properly model the complex behaviour of earthen walls (Soudani et al. 2016, Nowamooz and Chazallon, 2011, Bui et al., 2014).

In particular, the complexity in mechanical behavior of the material cannot be well described by the sole knowledge of a compressive strength and the apparent Young's modulus of the first loading (Champiré et al, 2016), while its thermal insulation potential may be significantly underestimated if it is only based on its thermal conductivity and heat capacity (Soudani et al., 2016).

In this context, the goal of this technical committee is to give an objective answer to these two questions by the definition of performance-oriented tests. These tests should depend on the use that will be made of the material, and their clear definition requires a good understanding of the specificities of earth, as well as the identification of the key parameters which drive its behaviour.

\section{Level of investigation}

The objective is to define the minimal number of laboratory tests in order to provide an accurate assessment of the mechanical, thermal and hygroscopic performances of the material. To that aim, whenever possible, existing experienced tests will be used. 
However, due to the particularities of the material, the development of new experimental protocols and/or the adaptation of existing ones may be necessary. These tests procedures and the way to analyse their results will be defined in the view of recent theoretical developments published in the literature and/or developed elsewhere by the members of the TC. The behaviour of the material is strongly impacted by the external conditions (temperature and humidity variations, saline environment, etc...). In consequence, the definition of dedicated tests to assess the performance of the material in some specific environmental conditions may be necessary.

The main importance will be given to the repeatability and the robustness of the tests. Round robin tests will be performed, and, in the function of the obtained results, the experimental protocols and even the nature of the test may be modified. The accuracy of the tests will be studied by comparing, at least qualitatively, their results to the onsite behaviour of earthen constructions. To allow this kind of confrontations, all the tested earths will come from existing constructions which are properly instrumented.

\section{Limit of the scope}

There are several ways to use earth in constructions (load-bearing walls, filling materials, plasters,...). This TC will be limited to load-bearing walls. However, several construction technics (rammed earth, CEB, adobe block, cob), made with unstabilized or lime/cement stabilized earths and with or without fibres will be studied. Whenever possible, the developed testing procedure would be such that they can be used for any of these constructions technics.

No standardisation activity, in its strict sense, will be made during the lifetime of this TC. However, all the experimental developments should be able to serve as a basis for the development of international/European standards on earth testing procedures

Finally, only experimental studies will be performed within the framework of this TC. All the theoretical developments required for this study have to be extracted from a bibliographic survey and/or realized elsewhere.

\section{Works in progress}

The first phase has consisted of analyzing with criticism the existing tests protocols for earthen materials. Several workgroups, composed by a dozen members, have been created to do that work. Each workgroup was driven by a member of the TC. The list of the working groups and the name of their leader is reported in the Table 1.

The members of the TC are currently working on a large campaign of round-robin tests. Its goal is to identify the more robust and accurate experimental protocols in order to measure the key mechanical and hygrothermal parameters of earthen materials (compressive strength and capacity, stiffness, dry density, thermal conductivity, water vapor permeability, water sorption capacity) as well as to assess their durability (resistance to abrasion and erosion). 
Table 1: Current working group of the TC.

\begin{tabular}{|l|l|}
\hline Working group & Leader \\
\hline $\begin{array}{l}\text { Overview of the existing standard on earthen } \\
\text { materials and constructions }\end{array}$ & $\begin{array}{l}\text { BV. Venkatarama Reddy } \\
\text { Indian Institute of Science }\end{array}$ \\
\hline Mechanical behaviour & $\begin{array}{l}\text { Jean-Claude Morel } \\
\text { Coventry University }\end{array}$ \\
\hline $\begin{array}{l}\text { Geotechnical and mineralogical characterization of } \\
\text { earthen materials, their meaning and their accuracy }\end{array}$ & $\begin{array}{l}\text { Jean-Emmanuel Aubert. } \\
\text { University of Toulouse }\end{array}$ \\
\hline Dynamic, seismic & $\begin{array}{l}\text { Quoc-Bao Bui } \\
\text { Ton Duc Thang University }\end{array}$ \\
\hline $\begin{array}{l}\text { Durability (water induced pathologies including } \\
\text { freezing-thawing, erosion, fire resistance) }\end{array}$ & $\begin{array}{l}\text { Domenico Gallipoli } \\
\text { University of Pau } \\
\text { Paulina Faria } \\
\text { NOVA University }\end{array}$ \\
\hline $\begin{array}{l}\text { Hygrothermal and acoustic behaviour of materials } \\
\text { (overview of the existing laboratory and on-site tests, } \\
\text { their robustness and their accuracy) + IAQ. }\end{array}$ & $\begin{array}{l}\text { Antonin Fabbri } \\
\text { University of Lyon }\end{array}$ \\
\hline
\end{tabular}

\section{CONCLUSION}

Unstabilised earth as a building material is not new material and has actually benefited of thousands of years of empirical validation which should give confidence to all the stakeholders to adopt unstabilised earth architecture for appropriate constructions less than four storey height. What is new is the socio-cultural context of the building industry, so that it is very important to be aware of the barriers and limitations of the material to successfully design and build earth architecture in Europe. To tackle the lack of testing procedures for materials of the earthen architecture, the Rilem TC 274TCE was created is 2016. However, this is only the first step to a better engineering approach of the specificity of earthen materials. Some further work will have to follow to integrate the current knowledge in standards.

\section{ACKNOWLEDGEMENTS}

The authors acknowledge all the members of the TC, listed in the following link https://www.rilem.net/groupe/274-tce-testing-and-characterisation-of-earth-basedbuilding-materials-and-elements-353

\section{REFERENCES}

Aubert, J.E., A. Fabbri, J. C. Morel, and P. Maillard, "An earth block with a compressive strength higher than $45 \mathrm{MPa}$ !," Construction and Building Materials, vol. 47, pp. 366-369, 2013.

Bui T.-T., Q.-B. Bui, A. Limam, and S. Maximilien, "Failure of rammed earth walls: 
From observations to quantifications," Construction and Building Materials, vol. 51, pp. 295-302, 2014.

Champiré F., A. Fabbri, J.C. Morel, H. Wong, F. McGregor, Impact of hygrometry on mechanical behavior of compacted earth for building constructions, Construction and Buildings Materials, vol. 110, pp. 70-78, 2016.

Floissac L, Marcom A and Morel JC 2010 Proc. 5th Urban Research Symposium (Marseille) World Bank

Hamard E, Cazacliu B, Razakamanantsoa A and Morel J C, Cob, a vernacular earth construction process in the context of modern sustainable building, Building and Environment, vol. 106, pp.103-119, 2016

Lei X., H. Wong, A. Fabbri, A. Limam, and Y. M. Cheng, "A thermo-chemo-electromechanical framework of unsaturated expansive clays," Computer and Geotechnics, vol. 62, pp. 175-192, 2014.

Loti G and Mecca S 2011 Terra Europae: Earthen Architecture in the European Union, (Pisa: ETS) 209p

Nowamooz H. and C. Chazallon, "Finite element modelling of a rammed earth wall," Construction and Building Materials, vol. 25, no. 4, pp. 2112-2121, Apr. 2011.

Morel, J. et al., Building houses with local materials: means to drastically reduce the environmental impact of construction', Building and Environment, vol. 36, pp. $1-7,2001$.

Soudani L., A. Fabbri, J.C. Morel, M. Woloszyn, P.A. Chabriac, H. Wong, A.C. Grillet, A coupled hygrothermal model for earthen materials, Energy and Buildings, Vol. 116, pp. 498-511, 2016.

Van Damme H., "Colloidal chemo-mechanics of cement hydrates and smectite clays : Cohesion vs Swelling”. London: Taylor \& Francis Group, 2006. 